\title{
Robots supporting play for children with physical disabilities: exploring the potential of IROMEC.
}

\author{
Renée J.F. van den Heuvel ${ }^{a, b}$, Monique A.S. Lexis ${ }^{a}$, Rianne M.L. Janssens ${ }^{a, c}$, Patrizia Marti ${ }^{d}$ and Luc \\ P. de Witte ${ }^{a, b}$ \\ a Zuyd University of Applied Sciences, The Netherlands (Research Centre for Technology in Care) \\ ${ }^{\mathrm{b}}$ Maastricht University, The Netherlands (CAPHRI, School for Public Health and Primary Care) \\ ' Zuyd University of Applied Sciences, The Netherlands (Faculty of Health, Department of \\ Occupational Therapy) \\ ${ }^{d}$ University of Siena, Italy (Department of Social, Political and Cognitive Science) and Eindhoven \\ University of Technology, The Netherlands (Department of Industrial Design)
}

Research Centre for Technology in Care, Zuyd University of Applied Sciences, Henri Dunantstraat 2, 6419 PB, Heerlen, The Netherlands, +31(0)88-0272120

Corresponding author: Renee.vandenheuvel@zuyd.nl

\section{Abstract}

Background: Play is essential for children's development. Children with severe physical disabilities often experience problems engaging in play. In rehabilitation and special education for children with physical disabilities play-like activities and play for play's sake are important.

Objective: The current study aimed at examining the possibilities of using the IROMEC robot in rehabilitation and special education for children with severe physical disabilities. 
Methods: A mixed methods approach, using individual interviews, two rounds of focus group interviews, a questionnaire and a final session to reach consensus, was used to examine the match between the goals in therapy and special education and the IROMEC robot.

Results: The existing play scenarios of IROMEC have the potential to support play for children with severe physical disabilities, especially in the domains of movement functions, learning and applying knowledge, communication/interpersonal interactions and relationships, and play.

Conclusions: The current study helped to build a body of evidence to the possibilities of the IROMEC robot. The results of this study can be used to further develop meaningful robotic play interventions for children with severe physical disabilities.

Keywords: robot, play, children, physical disabilities, special education, rehabilitation 


\section{Introduction}

Play is very important for children's development. Play can be defined as a structured or unstructured activity described in terms of how children use objects, pretend, socialize and interact with other people [1]. Children can develop sensory, motor, social, communicative and cognitive skills through play. Through play they explore their social environment and build up relationships [2]. Currently, more attention has been directed at the importance of play, especially for children with disabilities. A multidisciplinary network with 32 countries and almost 100 participants called 'LUDI Play for children with disabilities' aims to study the topic of play for children with disabilities and to spread awareness about the importance of providing children with disabilities opportunities to play (Action financed by COST European Cooperation in Science and Technology Action number TD1309) [3]. LUDI adopted the definition of play as proposed by Garvey (1990): Play is a range of voluntary, intrinsically motivated activities normally associated with recreational pleasure and enjoyment [4, 5].

Children with severe physical disabilities, as a consequence of, for example, cerebral palsy or acquired brain injury, commonly experience problems when engaging in play due to their physical limitations which are often accompanied by cognitive disabilities. These children experience significantly reduced participation in leisure activities and in physical play activities specifically. They are at life-long risk of health and social difficulties [6]. Most commercially available toys are not designed keeping in mind the requirements of these children, and therefore are difficult for them to manipulate. As a result, play activities may be partially or entirely impossible [7]. Play can be used to achieve theraputical or educational goals, e.g. in rehabitation and special education, but play can also be play for play's sake. There are already a number of examples of play devices, such as robots and ICT systems supporting play in children with severe physical disabilities. Some systems use playlike activities as a means to achieve external therapy and educational goals; others aim at play for play's sake. Examples of such systems include the Lokomat Pro System which aims to support 
motivation and gait pattern function, and the Interactive Rehabilitation and Exercise Systems (IREX) to support control of voluntary movement functions and carrying, moving and handling objects. The IROMEC robot has been developed to support play and attainment of goals related to general personal interactions which are closely related to play [8-11]. Since this robot has been showing to be a promising tool in supporting play, we decided to explore its possibilities for children with severe physical disability more thoroughly. Within the LUDI network, a database was created in which several potential robots and other tools and technologies to support play in children with disabilities are described [12]. When exploring the database, it is evident that there are not many toys on the market tailored to disabled children. Considering the characteristics of the described tools and technologies, IROMEC seems a promising robot to support play, and therapy and educational goals among children with severe disabilities.

IROMEC is a robot developed during the IROMEC (Interactive Social RObotic Mediators as Companions) FP6 European project between 2006-2009 (Figure 1). This European project investigated how a robotic toy can become a social mediator for children who are prevented from playing, due to cognitive, developmental or physical impairments [13]. Compared to other robots in this field, IROMEC has a unique combination of interaction possibilities using actuators, sensors, a touch screen and buttons to control the robot, which makes it suitable to the specific needs of this target group. One important outcome of this project was a set of ten play scenarios developed for children with severe motor impairments, children with mild mental problems and children with autism spectrum disorder. The play scenarios describe the use of the robot in a particular context. Five of these scenarios were actually implemented in the robot: turn taking, sensory reward, make it move, follow-me and get in contact [13]. In the next section of this paper and in figures 2,3 , and 4 these scenarios are described in more detail.

In the current study, the possibilities for application of IROMEC were studied for children with severe physical disabilities, since previous pilot studies have indicated that the robot may be a promising 
tool especially for this target group [14-16]. Interventions with the robot showed, for example, a positive impact on the level of playfulness [14]. A study with children with different levels of impairments showed encouraging results in terms of learning and enjoyment for children. Most of the improvements in this study have been observed in the motor development area [16]. The number of participants in these studies was relatively low, therefore it is worthwhile to further specify the application possibilities of the robot and to study the effects of the robot in larger groups of participants. However, besides positive results, several studies also reported shortcomings, mainly including the design of the robot. Besio et al. [15] demonstrated little added value for children with cerebral palsy, given the limited match between the children's needs in play and the robot itself as a toy. The main aim of the study presented in this paper was to study more thoroughly IROMEC's possibilities for children with severe physical disabilities. The research question was: Is the IROMEC robot suitable for application in rehabilitation and special education for children with severe physical disabilities? The results of this study are being used for a future pilot study with the robot.

\section{The robotic platform}

IROMEC is a mobile robotic platform developed to become a social mediator encouraging children with distinct levels of disabilities to discover a different range of play styles. It is addressed to children with autism spectrum disorder, children with severe motor impairments and children with cognitive disabilities. IROMEC was developed by Robosoft (www.robosoft.fr) to have controls related to movement, localization and navigationand is equipped with 13 ultrasound and 18 infrared sensors and a laser scanner to allow obstacle detection, navigation in space and reaction to external stimuli. Movement and speed are controlled through a motor/gearbox/encoder ensemble that makes movement safe and suitable for the interaction with children. The platform, which weights around 10 kgs, contains a video camera for colour tracking. The application module, developed by Profactor (www.profactor.at), manages the user interaction through a set of digital components and 
interfaces. It can be plugged on or unplugged from the mobile platform through hooks that safely and invisibly fasten the two modules. The interaction module measures $35 \times 55 \times 17 \mathrm{~cm}$ and weights around $8 \mathrm{kgs}$. The module is composed of two parts: the body and the head. The body displays graphical interface elements related to different play scenarios on a 13 inch digital touch screen. The body screen, for example, can represent the features of an imaginary cartoon-like character displaying a digital fur which moves according to the direction of the platform's movement. When the robot stops, fur clumps appear that extend when it moves again. The head is constituted of an 8 inch digital screen that displays the robot's facial expressions. Three wireless buttons connected via Bluetooth can be used by the children to control the robot and to play different games. The robotic platform can be configured to engage in a number of play scenarios as described in Figure 2. Marti (2010) described the scenarios in more detail, with supplementary images, which give a good insight into the course of the scenarios [17]. Figures 3 and 4 give a visual representation of two scenarios.

\section{Methods}

\subsection{Design}

A mixed method design using mainly qualitative assessments and an additional quantitative assessment was conducted. Individual interviews, focus group interviews (two rounds), a digital questionnaire and a final session to reach consensus were conducted, involving experts in the field of rehabilitation and education for children with physical disabilities. Together with the experts, relevant goals in the therapy and education for children with severe physical disabilities were explored and the possibilities for IROMEC interventions to support these goals were identified. The research activities and the accompanying aims of each of the activities are displayed in Figure 5.

3.2 Study context, participants and selection procedures 
The study was conducted in two Dutch rehabilitation centres and one primary school for special education. In the Netherlands, children with severe physical disabilities mostly attend these two kinds of institutions for therapy and education. Professionals participating in this research had no or very little experience with technology or robots in their work. One of the professionals worked with the IROMEC robot once before and some of them use technology like computers or Ipads in their therapy or education

In step 1, which included individual interviews and the first round of focus groups, the participants for the individual interviews were approached via a Dutch network for therapists and special educators who are 'pioneers' in the field of rehabilitation for children with Cerebral Palsy. The invitation for participation was disseminated via their online portal and e-mail. The first round of focus group interviews was organised with therapists and special educators from the participating organisations.

In step 2, the participants of step 1 were invited to complete the digital questionnaire which included a member check for the goals overview and was used to match the goals with the possibilities of the IROMEC robot.

In step 3, the second round of focus group interviews with experts was organised to match the goals with the possibilities of IROMEC with a larger audience.

In step 4, a final session to reach consensus was organised. The participating centres were represented by two people who already participated in the focus group sessions.

\subsection{Data collection}

\subsubsection{Interviews}

The professionals who agreed to participate were scheduled for an approximately one-hour 
interview with a trained interviewer (author $\mathrm{RH}$ ). The interviews included questions on what the most important goals for children with severe physical disabilities are and if and how the participants use the International Classification of Functioning, Disability and Health for Children and Youth (ICF-CY) [18] to determine goals and activities during therapy. Furthermore, questions were asked about the usage and importance of play to achieve these goals, and if they think the IROMEC robot could be suitable to contribute to these goals.

\subsubsection{First round of focus group interviews}

The focus group interviews were carried out by author $\mathrm{RH}$, assisted by a colleague with background in occupational therapy to take notes and to ask additional questions when needed. The goals and activities in therapy and education, the importance of play and opportunities for application of robots in their professional work setting were discussed. To create an overview of goals in therapy and education, the meta-plan methodology was used [19]. All participants were asked to write down all important goals for children with severe physical disabilities on separate memos without discussing with the others. Afterwards, these memos were categorised and discussed with the participants.

\subsubsection{Questionnaire}

A digital questionnaire was distributed among the participants who took part in the interviews and first focus group by e-mail. To increase participation, two reminders were sent. The questionnaire was used as a member check for the overview of goals created with the data from the individual interviews and from the first focus group [20]. Professionals were asked if the ICF-CY categorisation was correct and if the overview was complete according to them. Furthermore, after watching an IROMEC demo video, participants were asked to identify which goals IROMEC could address. In the demo video, the different scenarios and functionalities of the robot were displayed. 
The second round of focus group interviews was organised to discuss how the robot and its current scenarios could be matched with the overview of goals identified in the first round of focus groups. During these sessions first the researcher gave a demonstration of the IROMEC robot (see Figure 2). Participants were asked about spontaneous reactions regarding the application of the robot in their daily work. In addition to professionals, parents were invited via a Dutch client organisation for people with physical disabilities. These focus groups discussed the suitability of IROMEC for different kinds of disabilities, ages of the children and settings. Thereafter, a discussion was initiated regarding the possibilities for application of the robot to meet the goals used in therapy and education.

\subsubsection{Final session to reach consensus}

After the interviews, the first focus group interviews, the digital questionnaire and the second focus group interviews, a final session was organised together with five therapists and special educators who had also participated in the sessions described before. The aim of this final session was to reach consensus on initial practical application of the IROMEC robot: for which children and in which sessions they would apply IROMEC in the first instance and what requirements must be met before the robot can actually be applied in daily care practice.

\subsection{Data analysis}

The individual interviews and focus groups were audio recorded and transcribed verbatim. For the interview data and first focus group interviews a summary was written, and an overview of goals was created based on the transcripts and memos from the meta-plan methodology. This summary and goals overview were created by two researchers together to increase the credibility of the results. The questionnaire was used as a member check, in which the participants of the interviews and first round of focus groups got the opportunity to react on the goal overview and to make additions if needed [20]. 
For the second focus group interviews the researchers used the qualitative research software Nvivo 10 [21] to identify and code relevant fragments after carefully reading the transcripts. Based on the principles of conventional content analysis and directed content analysis a coding tree was created. The overview from the first focus group interviews (ICF-CY based) was used (directed content analysis) and additional codes derived from the data (conventional content analysis) [22]. Firstly, relevant fragments were labeled and and open coding took place. Secondly, axial coding took place and the fragements with the same codes were compared.

Different methods of data triangulation were used. Data were collected from different levels of participants (person triangulation). Furthermore, two researchers analysed and interpreted the data set to reduce the possibility of biased interpretation of the data (investigator triangulation) and multiple methods of data collection were used to gather similar and additional information (method triangulation) [20].

The answers on the digital questionnaire were exported to Microsoft Excel and descriptive statistics were used to describe these outcomes. The number of respondents choosing the relevant goals for application of the IROMEC robot comprised the quantitative data for this study.

From the final session, a summary of the results was written and checked by two researchers who were also present during this session, to make sure this was the complete overview of the session.

\section{Results}

\subsection{Data characteristics}

In step one, a total of 9 persons were interviewed, 2 males and 7 females. A combination of therapists and special educators working with children with physical disabilities participated, for example occupational therapists, a rehabilitation doctor, a child psychologist and a speech therapist. The working experience varied from 2 to 25 years. The first focus group interviews consisted of three 
sessions with a total of 17 individual participants. In all groups, therapists as well as special educators with a wide working experience (ranging from 2 to 37 years) with children with severe physical disabilities and different levels of cognitive abilities participated.

In step 2, the digital questionnaire was distributed to this entire group of 26 participants from the interviews and first round of focus group interviews. In total 10 participants completed the questionnaire anonymously.

In step 3 (second focus group interviews), six sessions included 25 participants in total, with a mix of special educators, therapists and one parent. Working experience ranged from 3 months to 32 years. In the final session (step 4), five people participated, including the therapists and special educators who participated in the earlier sessions. Table 1 displays an overview of the participants of step 1 to 4 with their working experience and gender.

4.2 Goals and application possibilities

The most important goals in therapy and special education identified in the interviews and first round of focus group interviews are displayed in the first two columns of Table 2. Domains of the International Classification of Functioning for Children and Youth (ICF-CY) were used to categorise the goals [18]. The participating professionals suggested to used the ICF-CY as a categorization tool because they are used to work with this framework when establishing goals. Categorisation was done by 2 researchers and all the participants of the questionnaire agreed with this categorisation. Since some subdomains of the ICF-CY came up as very relevant for this target group during the sessions, these domains were used as the main domains in this overview (Movement functions, engagement in play and education). The subcategories in the goal overview were not translated literally to ICF terminology; since the professionals should be able to recognise their own answers, their goal formulations were used. Professionals in the interviews and first round of focus groups indicated that using play with this target group is very important, for achieving all goals it is essential to use play activities because it makes it attractive to the children. All professionals are using play- 
like activities, but some of the professionals were also convinced of the importance of play for play's sake. In column two of Table 2, the goals presented in bold were identified in the questionnaire as the most promising goals (at least $50 \%$ of the participants thought this was a promising goal) for application of IROMEC. These goals were discussed in the second round of focus group interviews as well. Column 3 describes the number ( $n$ ) of participants who chose these goals as being 'promising'. Examples of how IROMEC could contribute to these most promising goals are displayed in the last column of Table 2. According to the professionals, e.g. eye-hand coordination could be stimulated by application of IROMEC with the alternative use of the three buttons which are part of the platform to perform tasks. This is part of the so-called 'make it move' scenario. Skills with regard to spatial awareness could be supported when the child controls the robot in order to explore the space around, also belonging to the 'make it move' scenario. Playing games together could be performed using for example the 'turn taking' game or the 'follow me' game.

\subsection{Improvement of IROMEC scenarios}

Besides the overview of goals and the possibilities for application of IROMEC, many suggestions for improvement of the robot and for new applications of the robot were reported. These suggestions were mainly general suggestions to improve the robot and the scenarios, and were not specifically linked to one of the existing scenarios. The most important suggestions can roughly be divided into three categories: suggestions concerning aspects related to the robot, concerning the context of the intervention and concerning the role of the professional. They are displayed in Table 3.

Suggestions regarding aspects related to the robot can be subdivided into appearance of the robot, control of the robot and new game ideas for the robot. Illustrating quotes related to these suggestions are displayed in Figure 6 and referred to in the text as e.g. Q1. The robot could be more attractive by using more colours (Q1), a more natural appearance and a 'dressing box' with several coats for the robot (e.g., a dog, a car) (Q2). Control of the robot could be elaborated with, for 
example, a joystick or speech recognition (Q3) and turning the robot should be easier (e.g. a grip attached to the robot) (Q4). Furthermore, the participants suggested numerous ideas for new games with the robot, e.g.; games with letters and numbers, robot being a memory aid and the robot providing instructions about daily life routines (dressing, eating etc.) (Q5).

A suggestion related to the context of the robot included that the robot should be able to be used inside as well as outside (Q6). Additionally, they mentioned that the robot should be suitable to be used in individual sessions as well as in group sessions $(Q 7, Q 8)$. Furthermore, the robot should be able to support educational sessions in the classroom with groups of children as well as group or individual therapy sessions.

The professionals indicated that they should be able to instruct the child with concrete tasks. Introduction and preparation of the child to the robot seemed important to them before starting to work with the robot (e.g., a picture of the robot in the classroom and explanation of its functioning) (Q9). Finally, the first session with the robot is important to get acquainted with the robot and to make the child feel comfortable (e.g., in this session goal setting should be of minor importance and it is important to let the child discover the robot).

In the final group session, the most important outcomes of the previous activities were discussed and a list comprising topics which are most relevant and urgent to change before starting to use the robot within a pilot study was created. The main conclusions of this session were that the existing play scenarios of the robot seem suitable for children with severe physical disabilities and worthwhile. The current scenarios of the robot were indicated to be most interesting for children between 2 and approximately 5 years old or older children with cognitive impairments. The 'turn taking for sensory reward' scenario was indicated as the least interesting, since the robot is not moving in this scenario and the robot does not seem to have an added value, compared to other possibilities in rehabilitation, e.g. using a computer. One of the most desired changes was related to the appearance of the robot. The initial design was kept very simple and neutral basically to address 
also the needs of children with autism spectrum disorder who were one of the three target groups of the European project IROMEC, as specified in section 2 above. The study presented in this paper shows the importance of adapting the robot features to the specific needs of the target audience. A robot design for children with autism spectrum disorder is unlikely to be accepted by children with physical disabilities who prefer a more attractive appearance and expression capabilities to get engaged in playing with the robot. Other relevant required changes were related to extending the opportunities to control the robot. For example the platform was required to be more flexible and adaptable to the preferences of the child in terms of speed change, and sound volume control. Futhermore, the emotions the robot displays should preferably be changed into the four basic emotions (happiness, sadness, fear and anger) which are the first emotions learned by children. An important remark mentioned by all the participants was that the best ideas for application will probably arise when testing the robot in real-life sessions with children. Currently, they can only speculate about possible applications; children's responses to the robot may be unpredictable.

\section{Discussion and Conclusion}

This study contributes to more insight into application possibilities for robots, especially IROMEC, for children with physical disabilities in rehabiliation and special education. The professionals participating in our study were very familiar with children with severe physical disabilities.

Professionals indicated that the most promising meaningful applications of IROMEC were related to the following ICF-CY domains: movement functions, learning and applying knowledge, communication/interpersonal interactions and relationships, and engagement in play. Thus, the professionals did see possibilities for meaningful application of IROMEC. Based on the demonstration, the functionalities and the scenarios of the robot were indicated to be the most promising for these goals. In the future, based on practical experiences of using the robot, other goals may appear interesting as well. The current functionalities and characteristics of the robot 
were evaluated as useful in supporting play for play's sake and play like activities in therapy as well as in a special education setting. Professionals came up with several ideas as described in the results section.

The goals overview corresponded with the domains of the ICF-CY [18] which is the common framework and language used in the field of therapy and special education. When having a closer look at the goals for application of IROMEC and the goals of other robots for children with severe physical disabilities, as reported in the literature, there are some more robots which concentrate on play or play related goals. The COSMOBOT for example is one of the few robots described in the literature as supporting movement functions, or the LEGO Mindstorms Tribot which aims at learning and applying knowledge [11]. This indicates that IROMEC may offer a meaningful addition to this field in terms of useful tools to support reaching therapy or educational goals for this target population. There are more platforms available on the market, however in the literature review described before, only robot platforms and ICT systems that have been evaluated scientifically were included [11].

As described in the results the professionals also came up with ideas how to improve the platform or the scenarios's to make application of the robot as meaningful as possible. Aspects related to the robot, related to the professional and related to the environment were described. Cook et al. [23] describe similar aspects in their paper in which they highlight design considerations for robots for children with disabilities. Appearance of the robot came up as very important as well, because it should be attractive for the children and personalized based on the preferences of a child. Furthermore, easy access to the interface was highlighted by Cook et al., which is comparable with the several control options which were suggested by our participants.

This study leads to requirements for designers which will help them to be create toys and robots for this target group. Furthermore, the study may create general awareness in professionals working 
with children with severe physical disabilities, and makes them aware of the kind of expectations they may have.

A strength of this study is the broad spectrum of professionals in therapy and education involved in the different steps, which contributes to the generalisability for a population of professionals working with children with severe physical disabilities. Furthermore, the actual experience with the robot during the demonstration session enabled them to have a good idea about the possibilities of using the robot. In this study only professionals and a parent were involved, since in this phase of the study these individuals are the most important to decide what the children need. In a next phase, children were involved to actually test the robot. This explorative pilot study with IROMEC was positively evaluated by professionals as well as the children and meaningful application possibilities were observed. Lacking adaptability, extensibility and technical stability of the IROMEC robot unfortunately make daily application and a large effect study with this specific robot impossible [24]. While application of robots is promising an meaningful for this target group future research should provide more insight into the actual application and feasibility of robots in rehabilitation and special education for children with severe physical disabilities.

\section{Acknowledgements}

This work was supported by a grant of the RAAK-PRO programme of SIA ("Stichting Innovatie Alliantie") for the project "Social robots in care" (project number PRO-4-10). This is a program from the Dutch ministry of education, culture and science to stimulate collaboration between public and private organisations. The authors would like to thank our colleague Gert Jan Gelderblom t for his highly appreciated contribution to this work. Furthermore, our acknowledgements go to the professionals who participated in this research and came up with numerous meaningful feedback and ideas. 


\section{References}

1. Spitzer S. Play in children with autism: Structure and experience. Play in Occupational Therapy for Children (2nd ed) St Louis, MO: Mosby Elsevier. 2008:351-74.

2. Besio S. Analysis of critical factors involved in using interactive robots for education and therapy of children with disabilities: Editrice UNI Service; 2008.

3. Besio S, Bulgarelli D, Stancheva-Popkostadinova V. Play Development in children with disabilities. LUDI publication in press. 2016.

4. Bulgarelli D, Bianquin N. Conceptual review of play. In: Besio S, Stancheva-Popkostadinova V. Play Development in Children with Disabilities. LUDI publication in press. 2016.

5. Garvey C. Play. Cambridge: MA: Harvard University Press.; 1990.

6. Kolehmainen N, Francis JJ, Ramsay CR, Owen C, McKee L, Ketelaar M, et al. Participation in physical play and leisure: developing a theory-and evidence-based intervention for children with motor impairments. BMC pediatrics. 2011;11(1):100.

7. Besio S. An Italian research project to study the play of children with motor disabilities: the first year of activity. Disability \& Rehabilitation. 2002;24(1-3):72-9.

8. Bryanton C, Bosse J, Brien M, Mclean J, McCormick A, Sveistrup H. Feasibility, motivation, and selective motor control: virtual reality compared to conventional home exercise in children with cerebral palsy. Cyberpsychology \& behavior. 2006;9(2):123-8.

9. Klein T, Gelderblom GJ, De Witte L, Vanstipelen S, editors. Evaluation of short term effects of the IROMEC robotic toy for children with developmental disabilities. Rehabilitation Robotics (ICORR), 2011 IEEE International Conference on; 2011: IEEE.

10. Koenig A, Wellner M, Köneke S, Meyer-Heim A, Lünenburger L, Riener R. Virtual gait training for children with cerebral palsy using the Lokomat gait orthosis. Studies in health technology and informatics. 2007;132:204-9.

11. van den Heuvel RJ, Lexis MA, Gelderblom GJ, Jansens RM, de Witte LP. Robots and ICT to support play in children with severe physical disabilities: a systematic review. Disability and Rehabilitation: Assistive Technology. 2015:1-14.

12. LUDI. Database of assistive technologies to support play for children with disabilities. 2016 [cited 201629 september]. from http://ludi.utad.pt/

13. Robins B, Dautenhahn K, Ferrari E, Kronreif G, Prazak-Aram B, Marti P, et al. Scenarios of robot-assisted play for children with cognitive and physical disabilities. Interaction Studies. 2012;13(2):189-234.

14. Bernd T, Gelderblom GJ, Vanstipelen S, De Witte L. Short term effect evaluation of IROMEC involved therapy for children with intellectual disabilities. Social Robotics: Springer; 2010. p. 259-64. 15. Besio S, Carnesecchi M, Converti RM. Prompt-fading Strategies in Robot Mediated Play Sessions. Proceedings of Assistive Technology: From Research to Practice, AAATE 2013: IOS Press Amsterdam; 2013. p. 143-p8.

16. Marti P. Bringing playfulness to disabilities. Proceedings of the 6 th Nordic Conference on Human-Computer Interaction: Extending Boundaries; 2010: ACM.

17. Marti $P$, lacono I. Learning through play with a robot companion. Proc 11 th European Conference for the Advancement of Assistive Technology, AAATE; 2011.

18. World Health Organization. International Classification of Functioning, Disability, and Health: Children \& Youth Version: ICF-CY: World Health Organization; 2007.

19. Schnelle E. The Metaplan-Method: Communication Tools for Planning and Learning Groups. Hamburg: Quickborn; 1979.

20. Polit D, Beck $C$. Nursing research: Generating and assessing evidence for nursing practice Ninth. Philadelphia, Pennsylvania Wolters Kluwer Health, Lippincott Williams \& Wilkins; 2012

21. Richards T, Richards L. NVIVO 10. [software]. Australia, QSR International Pty. 2008.

22. Hsieh H-F, Shannon SE. Three approaches to qualitative content analysis. Qualitative health research. 2005;15(9):1277-88.

Formatted: Dutch (Netherlands) 
23. Cook A, Encarnação P, Adams K. Robots: Assistive technologies for play, learning and cognitive development. Technology and Disability. 2010;22(3):127-45.

24. van den Heuvel RJ, Lexis MA, de Witte LP. Can the IROMEC robot support play in children with severe physical disabilities? A pilot study. International Journal of Rehabilitation Research. 2017. 


\section{Tables}

Table 1: Overview of participants

\begin{tabular}{lcccr}
\hline & Number & Male/female & $\begin{array}{c}\text { Average working } \\
\text { experience [years] }\end{array}$ & $\begin{array}{r}\text { Standard deviation } \\
\text { [years] }\end{array}$ \\
\hline Therapists & & & & \\
Occupational therpists & 8 & $1 / 7$ & 12.88 & 5.84 \\
Physiotherapists & 3 & $1 / 2$ & 25.67 & 6.03 \\
Speech therapists & 3 & $0 / 3$ & 20.00 & 8.66 \\
Group leaders early treatment & 3 & $0 / 3$ & 24.00 & 12.12 \\
Other & 5 & $1 / 4$ & 8.45 & 7.83 \\
\hline Educational participants & & & & \\
Teacher special education & 8 & $1 / 7$ & 16.75 & 10.93 \\
Teacher assistant & 4 & $0 / 4$ & 23.75 & 11.76 \\
Other & 2 & $2 / 0$ & 9.00 & 12.73 \\
\hline
\end{tabular}

Table 2: Overview of goals and possibilities for application of IROMEC

\begin{tabular}{|c|c|c|c|}
\hline ICF-CY Domains & $\begin{array}{l}\text { Goals and IROMEC } \\
\text { possibilities in bold }\end{array}$ & $n$ & Examples \\
\hline \multirow{5}{*}{$\begin{array}{l}\text { Mental functions } \\
\text { (B1) }\end{array}$} & Build up trust & 4 & \\
\hline & Experiencing own body & & \\
\hline & $\begin{array}{l}\text { To build a relationship and to } \\
\text { feel safe }\end{array}$ & 5 & $\begin{array}{l}\text { The robot can be used as a kind of friend. } \\
\text { Some children have problems with direct contact, the robot may } \\
\text { be a mediator in making contact with the child. }\end{array}$ \\
\hline & Imagination in someone else & 0 & \\
\hline & Social intercourse & 2 & \\
\hline \multirow{4}{*}{$\begin{array}{l}\text { Sensory functions } \\
\text { and pain (B2) }\end{array}$} & Sensory processing & 3 & \\
\hline & To watch & 9 & $\begin{array}{l}\text { To find the robot in the classroom/therapy room. } \\
\text { To watch the games when other children are playing with the } \\
\text { robot. }\end{array}$ \\
\hline & Balance & 0 & \\
\hline & Senso-motor skills & 4 & \\
\hline \multirow{4}{*}{$\begin{array}{l}\text { Movement } \\
\text { functions (B750- } \\
\text { b749) }\end{array}$} & Fine motor skills & 6 & To stimulate the use of buttons. \\
\hline & Gross motor skills & 7 & To walk behind the robot. \\
\hline & Eye-hand coordination & 8 & To stimulate the use of buttons. \\
\hline & Motor skills & 6 & To stimulate the use of buttons and walking against the robot. \\
\hline \multirow{5}{*}{$\begin{array}{l}\text { Leaning and } \\
\text { applying } \\
\text { knowledge (D1) }\end{array}$} & Spatial awareness & 8 & $\begin{array}{l}\text { The child may explore the space around him/her by using the } \\
\text { robot. }\end{array}$ \\
\hline & Learning & 5 & $\begin{array}{l}\text { To learn to understand the size of the room and to estimate } \\
\text { distances. } \\
\text { To learn how to manipulate the robot. } \\
\text { To send the robot to the right place. }\end{array}$ \\
\hline & Imitation & 7 & To imitate robot's movements. \\
\hline & $\begin{array}{l}\text { Planned and structured } \\
\text { working }\end{array}$ & 3 & \\
\hline & Concentration & 9 & To concentrate on finishing a game. \\
\hline
\end{tabular}




\begin{tabular}{|c|c|c|c|}
\hline & Problem solved learning & 3 & \\
\hline & Work attitude & 3 & \\
\hline & Making jokes and pretending & 3 & \\
\hline & Listening & 5 & To let the robot hide and to let it make sounds. \\
\hline & $\begin{array}{l}\text { Language comprehension and } \\
\text { expression }\end{array}$ & 4 & \\
\hline & Reading & 2 & \\
\hline & Numeracy skills & 2 & \\
\hline \multirow{7}{*}{$\begin{array}{l}\text { Communication } \\
\text { (D3) / } \\
\text { Interpersonal } \\
\text { interactions and } \\
\text { relationships (D7) }\end{array}$} & Turn taking & 5 & To stimulate turn taking and to teach turn taking behaviour. \\
\hline & Cooperation & 5 & To play games together. \\
\hline & Interaction & 8 & $\begin{array}{l}\text { To get in contact with the 'follow me' game. } \\
\text { To get in contact with each other via the robot, getting attention } \\
\text { via the robot. }\end{array}$ \\
\hline & Using voice & 3 & \\
\hline & Taking initiative & 6 & $\begin{array}{l}\text { To stimulate the child to take initiative otherwise nothing happens } \\
\text { (e.g., follow me, pressing buttons). } \\
\text { The robot can e.g. challenge the child to follow, to take initiative. }\end{array}$ \\
\hline & Get in contact & 6 & $\begin{array}{l}\text { To get in contact with the 'follow me' game. } \\
\text { To get in contact with each other via the robot, getting attention } \\
\text { via the robot. }\end{array}$ \\
\hline & Language & 3 & \\
\hline \multirow[t]{5}{*}{ Mobility (D4) } & Being able to move & 5 & To stimulate/motivate a child to move. \\
\hline & Climbing stairs & 0 & \\
\hline & Maintaining posture & 1 & \\
\hline & $\begin{array}{l}\text { Independent wheelchair } \\
\text { driving }\end{array}$ & 4 & \\
\hline & Being able to make transfers & 0 & \\
\hline \multirow[t]{5}{*}{ Self-care (D5) } & Dressing and undressing & 0 & \\
\hline & Eating and drinking & 0 & \\
\hline & Self help & 2 & \\
\hline & Independence & 3 & \\
\hline & Control skills & 6 & To use the buttons to control the robot. \\
\hline \multirow{7}{*}{$\begin{array}{l}\text { Engagement in } \\
\text { play (D880) }\end{array}$} & Playing independently & 5 & To stimulate play by using the robot. \\
\hline & Playing together & 5 & $\begin{array}{l}\text { To stimulate playing together, which may be more interesting with } \\
\text { use of the robot. }\end{array}$ \\
\hline & Fantasy play & 2 & \\
\hline & $\begin{array}{l}\text { Understanding of simple } \\
\text { rules }\end{array}$ & 6 & $\begin{array}{l}\text { Play should be the basis for application of the robot; if children } \\
\text { like it, other goals may be achieved as well. }\end{array}$ \\
\hline & Having play fun & 8 & $\begin{array}{l}\text { To motivate play. Play can be fun and predefined goals are not } \\
\text { always necessary. } \\
\text { In therapy, play is an important motivator. }\end{array}$ \\
\hline & Role play & 2 & \\
\hline & Competition & 3 & \\
\hline \multirow{3}{*}{$\begin{array}{l}\text { Education (d810- } \\
\text { d839) }\end{array}$} & Toddler skills & 3 & \\
\hline & Pre-school skills & 4 & \\
\hline & School skills & 2 & \\
\hline
\end{tabular}


Table 3: Suggestions for improvement of IROMEC scenarios

\begin{tabular}{lll}
\hline Aspects related to the robot & Aspects related to the context & $\begin{array}{l}\text { Aspects related to the behaviour of } \\
\text { the professional }\end{array}$ \\
\hline - Appearance & - Inside/outside use & - Concrete instructions to the child \\
- Control of the robot & - Group/individual sessions & $\begin{array}{l}\text { Introduction and preparation of the } \\
\text { child }\end{array}$ \\
- New game ideas & - Therapy/educational setting & - First session to let the child discover \\
& & the robot \\
\hline
\end{tabular}




\section{Figures}

\section{Figure 1. The IROMEC robot}

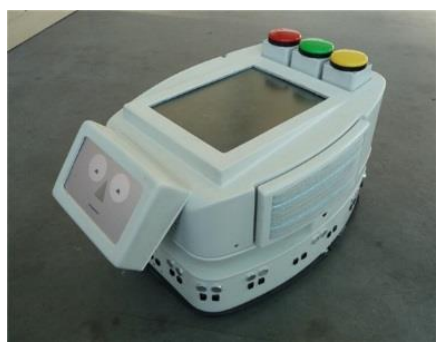

\section{Figure 2. Description of IROMEC and scenarios}

\section{IROMEC robot}

Before the demonstration the different technical components of the robot were introduced:

- Sensors

- Camera

- Touchscreen

- Screen (face)

- Wheels

- Moving lights

- Wireless buttons

\section{Scenarios:}

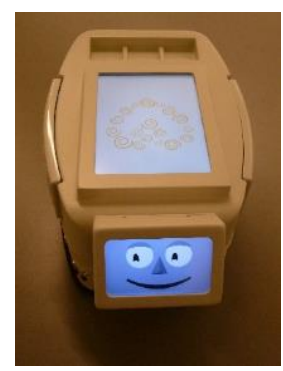

- Turn taking: Collaborative turn taking activity. Robot has start/stop activation mechanism that can be controlled by the user. First player turns the robot to face the second player and presses on the touch screen causing the robot to move to the second player. Robot stops at a predefined distance from the second player. The second players turns the robot around, presses on the touchscreen and sends it back.

- Turn taking for sensory reward: Two buttons (one for each player) to activate a corresponding sensory output display.

- Make it move: Pressing a green button to move the robot forward, a red button to turn right and an yellow button to turn left.

- Follow me: Robot starts to move searching for a child, when it finds a child it follows him/her within a predefined distance. If the child stops, the robot stops too. When the child and the following robot reach the second player, and the robot is closer to the second player, it starts to follow the second player.

- Get in contact: Therapist can select the robot's behaviour: Tactile mode (robot does not move, child may touch and explore the robots surface), fear (robot moves back with a scared face), communicative mode (robot tries to approach the child with a happy face) 
Figure 3. Turn taking

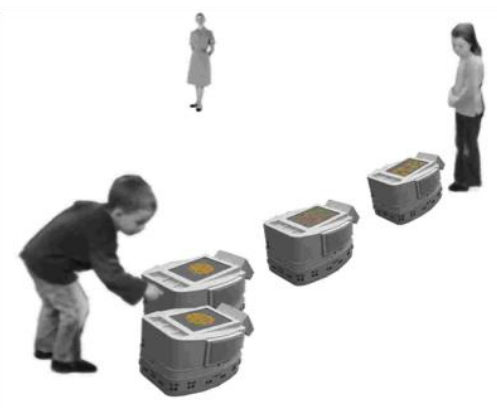

Figure 4. Follow me

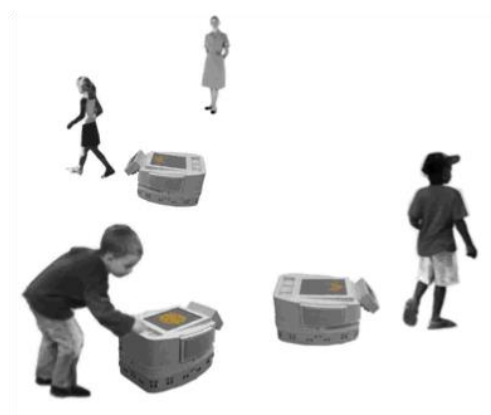


Figure 5: Research activities and aims

\section{Step 1: Interviews + Focus group interviews 1 (27 professionals involved)}

Aim:

To create an overview of goals in therapy and education important for children with severe physical disabilities.

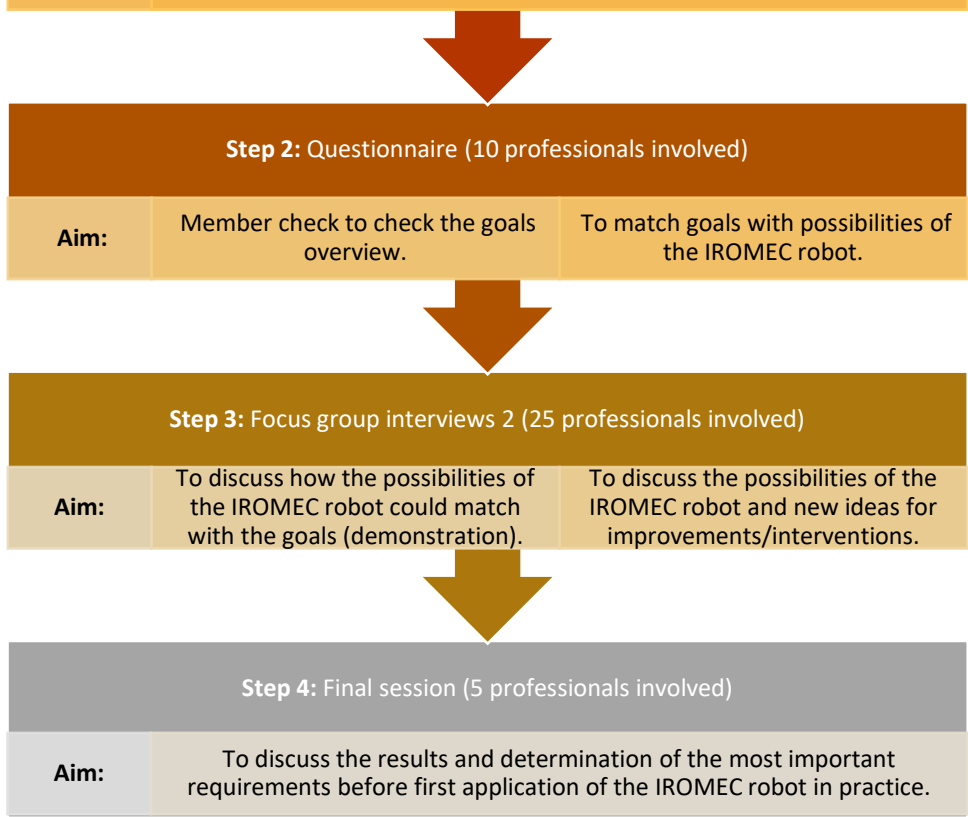


Figure 6. Illustrating quotes from the second round of focus groups

Q1 'You should definitely use the four basic colours in your design, those are the first colours to be recognised by our children'.

Q2 'The robot can behave the same, but if you change the coat of the robot it can be the witch today, tomorrow the dog and the day after the car'.

Q3 'I can imagine that you can train motor skills with for example button control, perhaps something with a joystick'.

Q4 'When you have to bend to turn the robot that is of course not very easy and comfortable. If there was a sort of handle it would be easier to turn'.

Q5 'I can imagine that something with reading will also be interesting. Using play to do something with letters. If you are not able to move yourself, but you can control the robot for example to combine letters into words or to combine digits, like a trail'.

Q6 'It is interesting for a child to follow the robot instead of one of us. Can the robot also go outside? Because I think that is important'.

Q7 'I was just thinking, when you have a group of children in a circle and you put the robot in the middle, the children can press the button and the robot moves towards the child. Then the child can send the robot to another child. I can imagine group games like that'.

Q8 'For every child there is another goal, so then you would use the robot individually'.

Q9 'I definitely think that we should prepare the children. That is very important. A new friend will come, let's sing a song for him. His name is... etc. Maybe showing a picture before'. 